\title{
ORIGINS OF WESTERN LITERACY
}

\author{
By Eric A. Havelock \\ Ontario, Canada: Ontario Institute for Studies in Education, \\ Monograph Series 14. 1976, vii-88, \$5.25
}

This monograph consists of four lectures delivered at the Ontario Institute by a noted scholar of the classics. Havelock has addressed the cultural consequences of literacy in greater detail in his work of the Prologue to Greek Literacy in which he developed some special insights into the consequences of schooling and literacy in ancient Greece. In these lectures, he updates his research and demonstrates how the development of the Greek alphabetic writing system has had some interesting consequences for the traditions of the western world.

There are some preconceptions about literacy that Havelock addresses in his opening chapter. It is this discussion that leads him naturally to the cultural significance of oral cultures in pre-literate Greece. At this time, 1100-700 B.C., the Greeks were preliterate and yet they had developed a highly complex form of social organization, numerous artistic achievements, and a tradition of philosophical thought. What this demonstrates is that civilization is not to be equated with literacy. Pindar and Plator, after all, were very close to total non-literacy. At the time of Aristotle, the work gramma meant "Having letters" and those who were agrammatos did "not have letters" or were illiterate. But, being illiterate does not mean that one is without language. Most of the languages of the world are without systems. Nevertheless, this treatment of language with literature still persists.

Another aspect of literacy discussed by Havelock involves the transition from the pre-Greek syllabary to the rise of the Greek alphabet. There are certain conditions which had to be met before this change would come about. First, there must be a suitable grapheme/phoneme correspondence. The characters used in the alphabet or in the syllabary must trigger the memory of the memory of the reader certain distinctive features. Second, the way in which these signs function must be unambiguous. One second shape or syllable unit must trigger only one phoneme. Third characters are

Another aspect of literacy discussed by Havelock involves the transition from the pre-Greek syllabary to the rise of the Greek alphabet. There are certain conditions which had to be met before this change world come about. First, there must be a suitable grapheme/phoneme correspondence. The characters used in the alphabet or in a syllabary must trigget the memory of the reader certain distinctive features. Second, the way in which these signs function must be unambiguous. One sound shape or syllable unit must trigger only one phoneme. Third, the total number of shapes must be held to a convenient level if the "democratization" of 
reading is to be possible. Usually, this means that about twenty to thirty characters are needed. Writing systems with more than these would be cumbersome; and, hence, it is not very surprising that the Semitic script, the Greek system of writing, and the Latin forms of orthography all were eventually reduced in number so as to suffice for the needs od public literacy. The Greek system, Havelock notes, was a true alphabet because it was the first and only system to meet all three of these conditions for reading. For this reason, Havelock believes that the Greeks did not just invent an alphabet; they invented literacy. It democratized the writing system and removed it from the elitistic status of sacred scribe.

This volume should be followed by a reading of Havelock's earlier work on literacy as well as by those of Ignatius Gelb on the Study of Writing and David Diringer on The Alphabet. All of these volumes provide the information summarized in this monograph and do so in greater detail and with stronger documentation. Futhermore, they relate the intriccacies of the Semitic script and other writing systems of the Near East to the rise of the Greek alphabet. The volume under review cannot be compared in the same light. It was done on the behalf of the Ontario Institute for Studies in Education as part of an honorary lecture series. The context of such a presentation does not naturally lend itself to the highly detailed accounts of the rise of literacy that the other volumes have so well expressed. Hence, these monograph should be viewed in these terms. Despite the restricted conditions under which such a delivery is made, Havelock has admirably summarized his overview and his insights on the origins of western literacy.

Reviewed by Robert N. St. Clair University of Louisville

\section{They hear you. You hear them. They can even hear themselves.}

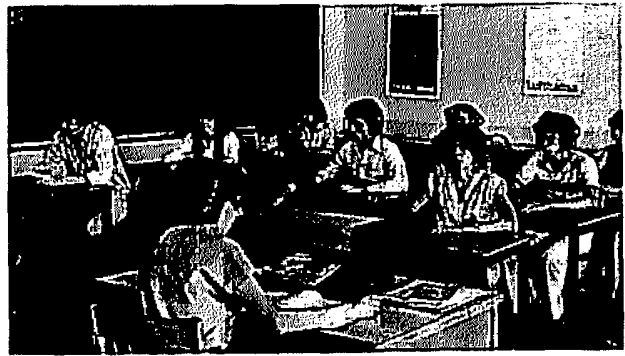

Teaching languages is more complete, and students develop more authentic speech skills with MoniCom III" electronic language laboratory. Three different languages or varied programs can be broadcast simultaneously. Students can be monitored, instructed or taperecorded from the console. The teacher can talk to each student privately, or play back an individual recording, without disturbing the class.

Moni-Com III uses solid state microelectronics for dependability, energy savings and low maintenance. Any number of students wearing headset/transceivers can participate with complete cordless seating flexibility. For a free, no-obligation demonstration from the leader in wireless instruction systems for language arts, contact: 


\title{
THE NEW LITERACY: THE LANGUAGE OF FILM AND TELEVISION
}

\author{
By Harold M. Foster \\ Urbana, Illinois: National Council of Teachers of English \\ 1979, viii-72
}

One of the problems that the classroom teacher encounters when dealing with literacy is the fact that he or she is a product of the book-oriented world of the print culture whereas their students have come to see and understand the world around them through television. This separation of the print culture and the electronics culture has some interesting implications for curriculum designers, school administrators, and classroom teachers. These implications have to do with a shift in cognitive styles and other forms of human information processing. The teacher prefers the analytical mode of

One of the problems that the classroom teacher encounters when dealing with literacy is the fact that he or she is a product of the book-oriented world of the print culture whereas their students have come to see and understand the world around them through television. This separation of the print culture and the electronics culture has some interesting implications for curriculum designers, school administrators, and classroom teachers. These implications have to do with a shift in cognitive styles and other forms of human information processing. The teacher prefers the analytical mode of cognition which the process is linear, rational, and logical. The student, on the other hand, feels more comfortable with the relational mode of cognition and processes information in terms of simultaneous patterns or Gestalts. They are more affective in dealing with visual information tend to recognize and interpret emotions more readily. When faced with this new form of literacy, it is only natural that educators have already begun to address the significance of using film and television in the classroom setting.

The first part of this focus on visual literacy is addressed to defining and analyzing the basic structures used in the making of film. This concern with media manipulation is understandable since the student who knows the tools of literacy can do a better job in controlling them when processing visual information. They will be able to recognize how a visual image is composed or arranged through the use of close-ups, long shots, camera angles, framing, and zoom shots. They will learn how lighting alone may convey feelings, or how motion can have a hypnotic attraction in some scenes and emotive force in another. Even sound will become a factor in their lives as they will begin to sense the tremendous effect of silence in some scenes or the rhythmic trance of music in others. Films convey a strong sense of reality and leave those in the audience with the illusion that seeing is believing. By learning about the language of film, the student can gain a sense of visual literacy. They will learn 
how to create the illusion of movement, and the persistence of vision. They will recognize also how other editors have altered reality for them when viewing a film as part of the audience. Film, after all, is the product of manipulation. It is done by creating a sense of time and space and be developing a mood through color and music and movement. In teaching about the language of film, Foster has a section on the making of a film called High School. It was done over a decade ago in the Philadelphia area using the cinema verite treatment. The theme throughout the film is that the school system is oppressive, militaristic, sterile, cold, and banal. To create this mood, the editor interspiced scenes of military regimentation. The switch between the soldiers following orders and the high school students responding to the demands of their teachers created a strong visual effect. It equated the teacher with a drill sargeant. When the students from this school were interviewed, they underscored the impact of the illusion of filming. The producer, for example, concentrated on only those teachers who met with their preconceived notions of the high school as indoctrination. Other scenes were just simply left out when they did meet with their stereotype of the system. What these omissions demonstrate is that film making is a form of agenda setting. The editor determines what issues are going to be discussed and which ones are not. A visually literate person would be able to recognize this and to counter the illusion through his or her knowledge of the experience and the language of film production.

The second part of the book concerns the teaching of visual literacy skills as part of the high school curriculum. Foster believes that this is a responsibility of the teacher, and more specifically of the teacher, and more specifically of the teacher of English. If verbal literacy belongs to the composition teacher, he argues, then visual literacy should also be a part of his or her duty in the teaching of communicative skills. This argument speaks more from tradition than from logic. The fact that Foster is a teacher of English and that the publication was sponsored by a national organization for teachers also accounts for the rationale of his argument. Nevertheless, this section of the book is rather informative. It deals with the process of selecting materials, the kinds of film journals the teacher should become familiar with, teaching approaches to avoid, and numerous other classroom activities such as how to read a film, how to recognize the structural elements of film, the creation of illusions, film criticism, satire, and film scripting. The student is allowed to develop a critical sense of film as documentary, propaganda, advertising, portrayal, and so on.

This volume on the new literacy should be of immediate assistance for the teacher who is beginning to venture into the world of film and television and its impact on the classroom. It is a very practical guide for the inservice teacher. It is not to be used as an actual classroom text, but it will be an excellent guide for the teacher who is preparing for a class on visual literacy. It can be supplemented by other volumes dealing with film history, film criticism, film production, 
biographical accounts of famous film makers, film journals, script writing, and so on. The new literacy, therefore, can be a most effective guide into this new venture. Its lengthly bibliography naturally leads to an ever widening experience into the world of film and television.

Reviewed by Robert N. St. Clair

University of Louisville

\section{NATHONAL ABSOCLATON OF LANGUAGS haDORATORT DIRECTORS NALR JOULNal}

Name

Title

Institution

Address to which NALD JOURNAL is to be sent:

Address

City
MMTIBURSHIP

口n Nom

North America

U.S./Can/Mexico

All libraries +

Foreign air mail

Students

$\$ 15$

$\$ 5$

Sustaining

Members

Return this form to:

Office of Academic Publications 240 Gardiner Hall

University of Louisville Louisville, Kentucky 40292 


\title{
TEST LESSONS IN READING FIGURATIVE LANGUAGE
}

\author{
By William A. McCall, Edwin H. Smith, \& Barbara C. Palmer \\ New York: Teachers College, \\ Columbia University, 1980 vi-170.
}

In literature classes, one hears about such figures or speech or tropes such as similes, metaphors, incarnation, and hyperbole. Usually, it is assumed that figurative language belongs to poetic expression or rhetorical devices; however, as the authors of this classroom text demonstrate, these forms of linguistic creativity are common to everyday language. Their concern is not to teach people how to classify these patterns of expression, but to provide an aid for students so that they will be able to better recognize, interpret, and differentiate good tropes from poor ones.

The exercises employed in the teaching og the various figures of speech varies. Some involve a short paragraph in which tropes are presented in italics. Upon the completion of the reading, they are required to clarify just what the metaphor means in the context of the story. They are asked to select from several possible answers. For example, if the simile used in the passage is "Advice is like snow," they are to decide whether this means that "it does not last" or that "it should be given gently" or that it "is misleading." Since snow falls softly and dwells on the ground before accruing some depth, one could readily assume that the meaning of this simile is that advice should be given gently. Certain exercises are of the fill-in-the-blank form. The student must choose the best form that goes with the passage. Not all of the exercises are of the recognition and recall type. Some of them require the student to create metaphorical expressions from an established pattern. These are, in essence, extensions of other metaphors.

The kinds of tropes discussed also vary throughout the text. These include animal similes, personification, ontological or sense metaphors, hyperbole or overstatement, litotes or understatement, irony, literacy incarnations, synecdoghe or the substitution of one entity for a related part, euphemisms, metonymy or the replacement of one element for related form, and other tropes. The lessons on spoonerisms and malapropisms are not intrinsically related to other forms of figurative language and were included by the authors for levity and personal interest.

Many students have been introduced to these various forms of figurative language in their literature classes when studying either English or some other language. Usually, the forms themselves were presented as a part of some literary discussion and the examples were beyond the general experiences of these students unless they were majoring in language and literature. Given this normal state of affairs, this volume on figurative language is informative. It enables the uninitiated to come to learn about metaphors and other tropes by practicing with these various forms in a workbook context. They will not only be able to classify them more effectively, but these students 
will also be able to recognize and interpret them with greater ease. Hence, the workbook approach to studying tropes fills a definite need in the area of language teaching.

For the foreign language educator who is faced with the problem of teaching his or her students how to use and recognize figurative language, this textbook can provide an interesting model for their own project on developing classroom materials. It offers a wide range of kinds of language structures and classroom exercises. It also provides an interesting range of reading passages in which metaphoric expressions are embedded. Finally, this volume can also be used as a self-directed learning exercise to complement other literary discussions. If there is a weakness in this work, it has to do with relating these various tropes with the writing process. This was not what the authors intended in developing this text, however, it is a need that should be seriously entertained as writing is just as important a literacy skill as reading. Unfortunately, the textbook only focuses on the latter. Nevertheless, this book does have many immediate uses for the language teacher. Another potential expansion of this volume should be mentioned in addition to the concern for the use of tropes in the writing process. This other area of interest involves the use of slides, videotapes, or other forms of visual information from which students should be required to create and to recognize various tropes. One could easily handle such concepts as euphemisms, litotes, hyperbole, personification, and other forms of figurative language through pictures, slides, or other visual metaphors.

Robert N. St. Clair

University of Louisville 